\title{
Comprehensive update on carbon nanotubes and their significances in the field of pharmaceutics
}

\begin{abstract}
Carbon Nanotubes are carbon allotropes with nano size range that have a lengthto-diameter ratio up to $132,000,000: 1$. These cylindrical molecules were a unique dominion that makes them favorable in pharmaceuticals and nanotechnology. However, structurally they showed like cylindrical graphene sheets of $\mathrm{sp} 2$ bonded carbon atoms. They exhibit unique mechanical properties like high toughness and high tensile strength. Moreover, various methods have been refined to produce nanotubes in required and controlled quantities. Carbon nanotubes were found much utilization in medical research and pharmacy like when incorporated with various drugs they can be utilized as a carrier for drug delivery. They can also be utilized for boosting up of bio imaging genomes, proteomics and tissue engineering. However, CNTs possessed antioxidant properties and also showed preservative effect. When incorporated with magnetic materials, radioisotope enzymes, they can also be utilized as biosensors for diagnostic purposes and also for the monitoring of hazardous radiations in nuclear plant/reactor.
\end{abstract}

Volume I Issue 3 - 2016

\author{
Karandeep Singh,' Mahendra Rana,' Sumit \\ Durgapal,' Amita Rana,' Suraj Pratap Verma,' \\ Vinit Raj ${ }^{2}$ \\ 'Department of Pharmaceutical Sciences, Kumaun University, \\ India \\ ${ }^{2}$ Department of Pharmaceutical Sciences, Babasaheb Bhimrao \\ Ambedkar University, India
}

\begin{abstract}
Correspondence: Vinit Raj, Department of Pharmaceutical Sciences, Babasaheb Bhimrao Ambedkar University, Vidya Vihar,
\end{abstract} Rae Bareli Road, Lucknow-226025, Email raj.vinit24@gmail.com

Received: November 21, 2016 | Published: December 30, 2016

Keywords: carbon nanotubes, cnts, functionalization, dispersion, synthesis, analysis, toxicokinetic, applications

Abbreviations: CNTs, carbon nanotubes; 3D, third dimension; $\mathrm{nm}$, nanometer; $\mathrm{C}_{60}$, buckminsterfullerene; TEM, transmission electron microscopy; SWNTs, single walled carbon nanotubes; MWNTs, multiple walled carbon nanotubes; ${ }^{\circ} \mathrm{C}$, degree centigrade; $\mathrm{Co}$, cobalt; Ni, nickel; Fe, iron; Y, yttrium; CVD, chemical vapour deposition; PECVD, plasma enhanced chemical vapour deposition; $\mathrm{C}_{2} \mathrm{H}_{2}$, ethylene; Mo, molybdenum; V, vanadium; FePc, iron phthalacyanine; $\mathrm{C}_{4} \mathrm{H}_{4} \mathrm{~S}$, thiophene; $\mathrm{HNO}_{3}$, nitric acid; $\mathrm{ZrO}_{2}$, zirconium dioxide; $\mathrm{CaCO}_{3}$, calcium carbonate; $\mu \mathrm{m}$, micrometer; $\mathrm{CS}_{2}$, carbon disulfide; $\mathrm{CF}_{4}$, tetra fluoromethane; $\mathrm{COF}_{2}$, carbonyl fluoride; $\mathrm{GCP}$, gel permeation chromatography; HPLC-SEC, high performance liquid chromatography-size exclusion chromatography; SWNHs, single walled nanohorns; EPO, erythropoietin; DNA, deoxyribonucleic acid; VP1, viral protein 1; FMDV, foot-and-mouth disease virus; CNHs, carbon nano horns; SED, surface-conduction electron-emitter display

\section{Introduction}

Until the mid-1980's it was believed that pure carbon exists in only two physical forms, Diamond, and Graphite. These forms have different physical geometry and dominions however their atoms in $3 \mathrm{D}$ space are arranged in covalently bonded mesh. These two physically and structurally distinct forms of carbon atoms are labeled as allotropes.

In last few decades, the curiosity regarding the discovery, development and, large-scale manufacturing and production of novel materials that lie within the nanometer dimensions has been increased. Such nanomaterials can be of organic or inorganic origin and most of them have not been much studied in the context of pharmacy. Carbon nanotubes (CNTs) are among one of them. CNTs are allotropes of carbon. Key dominions of Carbon nanotubes are as follows:

A. They are tube-like structures, made of graphite.

B. They are not more than $100 \mathrm{~nm}$ in diameter and can be as thin as 1 or $2 \mathrm{~nm}$.
C. They can be employed chemically and physically in useful ways.

D. They are having a wide range of utilization in materials science, pharmaceutics, chemical processing, energy management, electronics, and many other fields.

These properties vary with kind of nanotube formed, defined by its diameter, length, chirality and arrangement of atoms in the wall. CNTs inherit various novel and unique dominions that make them advantageous in the field of pharmaceuticals and nanotechnology. ${ }^{1}$

\section{Historical background}

In 1985, a group of researchers guided by Richard Smalley and Robert Curl of Rice University and Harry Kroto of Sussex University independently discovered an interesting thing during their researchers. They vaporized a specimen of graphite with a fierce pulse of laser light and utilized helium gas to transfer the vaporized carbon into the mass spectrometer. The mass spectrum unfolded some peaks akin to the bundles of carbon atoms, with a particular intense peak akin to molecules composed of 60 carbon atoms, $\mathrm{C}_{60}$.

This newly formed cluster lead the group to propose that a new form or allotrope of carbon had been discovered. It was a sphere like a football with 32 faces. Out of 32 faces, 12 were pentagons and 20 were hexagons.

After this discovery, other related molecules were also explored and they along with bucky balls were recognized as new allotropes. This newly discovered class of carbon molecules was named as fullerenes. Fullerenes are the molecules consisting wholly of carbon in the form of a hollow sphere, ellipsoid or tube, they consist of a series of interlocking hexagons and pentagons. ${ }^{2}$

It was also found that these carbon atoms can form long cylindrical tubes, these tubes were initially termed as "buckytubes" but now known as carbon nanotubes or CNTs. Carbon nanotubes (CNTs) 
were unveiled in 1991 by Sumio Ijima in Tsukuba, Japan, during high-resolution transmission electron microscopy (TEM) observation of soot generated from the electrical discharge between two carbon electrodes. The discovery was accidental, although it would not have been possible without Ijima's excellent microscopist skills and expertise. Ijima discovered that under different experimental conditions, carbon atoms can instead self-assemble into CNTs. ${ }^{3}$

\section{Classification of carbon nanotubes}

Carbon nanotubes are classified into following two types: (Table $1)^{1-5}$
A. SWNTs - Single Walled Carbon Nanotubes
B. MWNTs - Multiple-Walled Carbon Nanotubes

Table I Comparative Study of Swnts and Mwnts

\begin{tabular}{|c|c|c|}
\hline S No & SWNTs & MWNTs \\
\hline I & Discovered by donald bethune, in 1993 & Discovered by Sumio lijima, in I99I \\
\hline 2 & SWNTs have their outer diameter in the range $0.6-2.4 \mathrm{~nm}$. & $\begin{array}{l}\text { MWNTs generally have their outer diameter in } \\
\text { the range of } 2.5-100 \mathrm{~nm} \text {. }\end{array}$ \\
\hline 3 & Made by rolling single layer of graphene & $\begin{array}{l}\text { Made by rolling multiple layers of graphene } \\
\text { with an inter layer separation of about } 0.3 \mathrm{~nm} \text {. }\end{array}$ \\
\hline 4 & Catalyst is required for production & Can be produced without catalyst \\
\hline 5 & $\begin{array}{l}\text { Bulk synthesis is difficult since it requires proper control over growth } \\
\text { and atmospheric conditions. }\end{array}$ & Bulk synthesis is easy. \\
\hline 6 & Purity is poor & Purity is high \\
\hline 7 & Chances of defect are more during functionalization. & $\begin{array}{l}\text { Chances are less but once happened it is } \\
\text { difficult to improve. }\end{array}$ \\
\hline 8 & Fewer conglomerations in body. & More conglomerations in body. \\
\hline 9 & Characterization and evaluation is easy & It has very complicated structure. \\
\hline 10 & It can be easily tangled and more flexible. & It cannot be easily tangled. \\
\hline
\end{tabular}

\section{Chirality or geometry of carbon nanotubes:}

There are three different geometries of CNTs. The three unique geometries are also called as flavors. The three flavors are armchair, zig-zag, and chiral [e.g. zig-zag (n, 0); armchair (n, n); and chiral (n, $\mathrm{m}$ )]. These flavors can be differentiated on the basis of how the carbon sheet is wrapped into a tube.

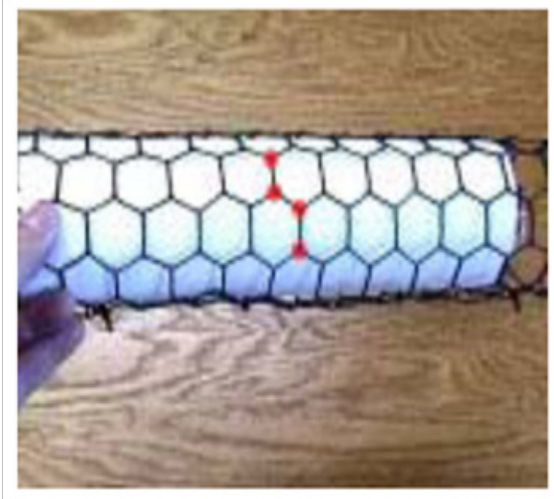

A. Arm chair arrangement of carbon atom.

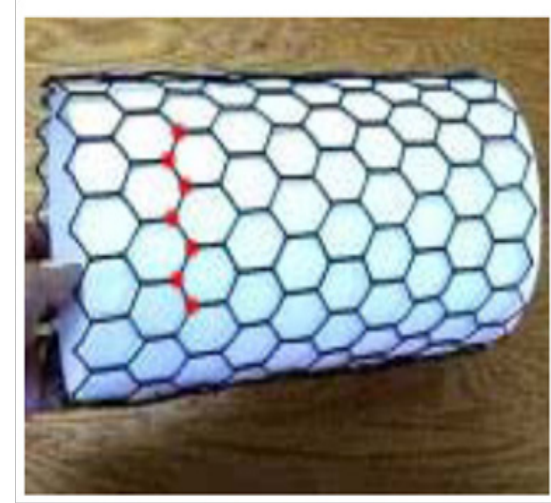

B. Zig-zag arrangement of carbon atom.

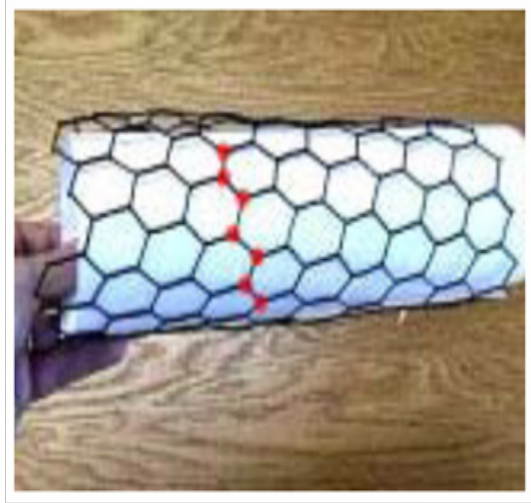

C. Chiral arrangement of carbon atom

Figure I Different arrangement of carbon atom.

The chirality of SWNTs is important and concludes their conductivity, for their potential development into a huge variety of SWNT-based electronic switching devices. ${ }^{4}$ One of the important physical dominions of carbon nanotubes is that it is possible to manufacture them only a single layer thick. This implies that they can be about $1 / 50,000^{\text {th }}$ the thickness of a human hair.
The chirality of an SWNT is defined by a pair of integers (n, m) which is derived from the 3D arrangement of graphite hexagons with respect to the SWNT axis. The chiral vector $(n, n)$ in arm chair arrangement is perpendicular to the tube axis as shown Figure 1A whereas in Figure 1B, the chiral vector (n, o) is V- shape perpendicular to the tube axis. All other arrangements except armchair and Zig Zag are known as chiral or helical compositions, Figure 1C.

\section{Production of carbon nanotubes}

CNTs are widely manufactured by following techniques:
A. Arc discharge method
B. Laser ablation method 


\section{Chemical vapor deposition \\ D. Other methods ${ }^{6}$}

Arc discharge method: Arc discharge method was first used by Iijima in 1991 exclusively for the production of CNTs. This technique (Figure 2) produces both SWNT and MWNT at the same time, therefore, this method requires separation of required CNT from the soot.

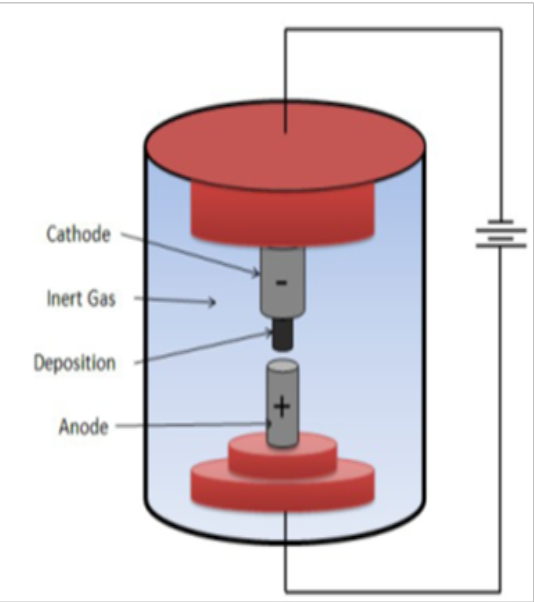

Figure 2 Arc discharge method.

This technique involves vaporization of graphite anode rod and deposition of the carbon soot on the cathode rod under an inert atmosphere. Graphite rods with $99.99 \%$ purity are used. Major impurities in graphite are sulfur atoms as sulfur changes the morphology of CNTs. The anode is a long rod of $6 \mathrm{~mm}$ diameter $\&$ the cathode is a short rod of $9 \mathrm{~mm}$ diameter. When pure graphite electrodes are used then MWNTs are obtained but when anode doped with some catalyst material like Ni, Co etc are used then SWNTs are produced. Helium and argon have a different diffusion coefficient and thermal conductivities, these dominions affect the nanotube diameter in the arc process. ${ }^{7}$

Laser ablation method: MWNTs were relatively easy to develop as compared to SWNTs therefore, in 1996; Smalley et al. successfully developed laser ablation method (Figure 3) for mass production of SWNTs.

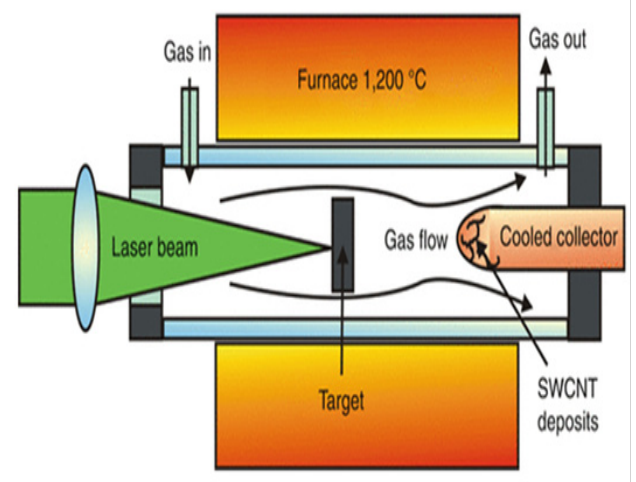

Figure 3 Laser ablation method.

A pulsed or continuous laser is utilized to vaporize a graphite target in an oven at $1200^{\circ} \mathrm{C}$. Hazy, scattered feather like hot vapors form, that expands and cools rapidly. As this plume cools, small carbon molecules and atoms rapidly aggregate to form larger clusters, including fullerenes and other soot material. It should be kept in mind that if pure graphite electrodes are used, MWNTs would be obtained, but if an alloy of graphite including one or more catalysts like Co, $\mathrm{Ni}, \mathrm{Fe}$ or $\mathrm{Y}$ was used then uniform SWNTs could be synthesized. From these clusters, tubular molecules develop into SWNT until the catalyst particles become too large, or until conditions have changed sufficiently that carbon cannot diffuse through the surface of the catalyst particles. It is also possible that the particles become that much coated with the soot layer that they cannot absorb much radiation and the nanotubes resist growing. The SWNTs formed, in this case, are clustered together by Vander Waals forces. Nanotubes obtained by laser ablation are relatively purer (up to about $90 \%$ purity) than those obtained from arc discharge process. The $\mathrm{Ni} / \mathrm{Y}$ catalyst mixture in the ratio $4.2 / 1$ gives the best yield. ${ }^{8}$

The size of the SWNTs obtained from this technique ranges from 1-2 nm, for example, SWNTs of size range 1.3-1.4 nm are obtained when $\mathrm{Ni} / \mathrm{Co}$ catalyst with a pulsed laser at $1470^{\circ} \mathrm{C}$ was used. In the case of a continuous laser at $1200^{\circ} \mathrm{C}$ and $\mathrm{Ni}$ : Y catalyst in the ratio 2:0.5 is used, SWNTs with an average diameter of $1.4 \mathrm{~nm}$ were formed with $20-30 \%$ yield. ${ }^{9}$

Chemical vapor deposition: Arc discharge method which was earlier used for the synthesis of CNTs was not sufficient to produce tubes of high purity, so efforts were made in developing a new method which could produce CNTs of high purity with controllable growth and the scientists come up with Chemical vapor deposition (CVD) technique (Figure 4).

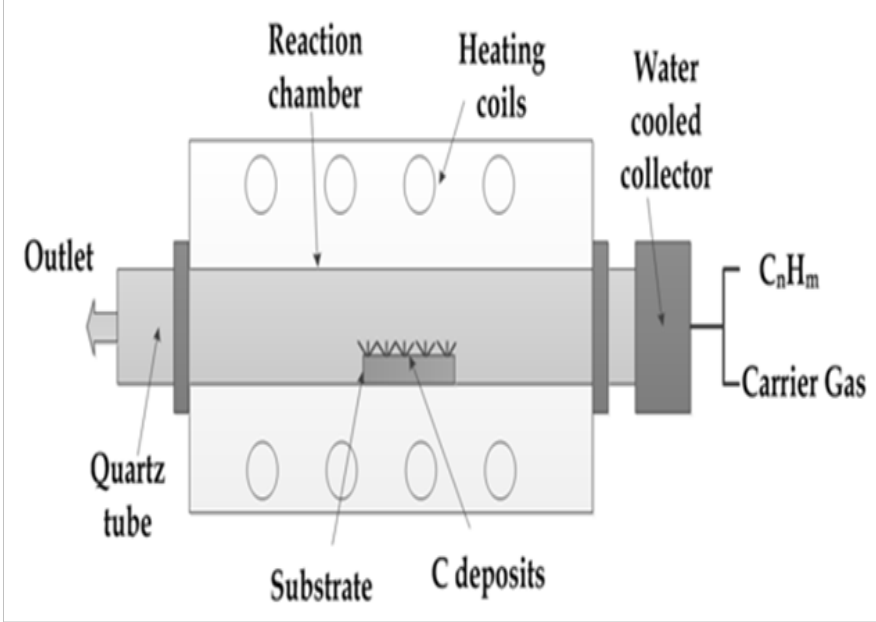

Figure 4 Mechanism of chemical vapour deposition.

CVD technique was a completely different method as compared to arc discharge and laser ablation method. Earlier methods employed the utilization of high-temperature condition and less reaction time but CVD as compared to arc discharge method and laser ablation can be worked out on medium temperature conditions and more catalytic condition reaction time. ${ }^{10-12} \mathrm{CNTs}$ are synthesized by putting a carbon source in the gas phase and using an energy source, such as plasma or resistively heated coils, to transfer energy to gaseous carbon molecules. The power source is utilized to unveil reactive carbon species of molecule. If proper parameters and conditions are maintained then high-quality CNTs are obtained. Excellent alignment of CNTs and positional control on a nanometer scale can be acquired 
by utilizing this technique. Type of CNT is dependent on the nature of the metal catalyst. ${ }^{13,14}$

The temperatures used for the synthesis of nanotubes by CVD technique is usually in the range of $650-900^{\circ} \mathrm{C}$. Typical yield of high purity CNT for CVD is approximately $30 \%$. One of the prime benefits of this technique is that the nanotubes obtained from this technique are so pure that no further purification is required; they can be utilized as such. In the last decade, contrasting methods for the carbon nanotubes synthesis with CVD have been developed, like plasma enhanced CVD, thermal CVD, catalytic pyrolysis of hydrocarbon and laser assisted CVD. ${ }^{15}$

Plasma enhanced CVD (PECVD): PECVD is an assuring growth technique for the vertical alignment and selective positioning of CNTs. For being an excellent field emitter vertical alignment is an important property, this property find application in flat panel displays. The idea behind selecting plasma processing is to avoid the dissociation of precursor as observed by highly energetic electrons and as a result, the substrate temperature can be substantially lowered as compared with thermal CVD.

The CNTs has been successfully processed from various plasma techniques such as hot filament PECVD. ${ }^{16-19}$ microwave PECVD, ${ }^{20-24}$ D.C. (glow discharge) PECVD. ${ }^{25-27}$ and inductively coupled PECVD $^{28,29}$ and Rf PECVD. ${ }^{30-32}$ It is evident from above methods that PECVD is a high yield and controllable method of producing vertically aligned CNTs.

Thermal CVD: A thermal CVD reactor consists of a quartz tube enclosed in a furnace and is inexpensive to construct. The material used for substrate may be $\mathrm{Si}$, silica quartz or alumina. The nature of the catalytic metals and their supports affects the yield of the CNTs; other important factors that also affect the yield include the hydrocarbon sources, the gas flows, the reaction temperature, and the reaction time, etc. It is possible to design the chemical and physical properties of the CNTs according to the need in advance by taking care of the proper conditions for their manufacturing. This technique is mostly used for growing MWNTs, it utilizes acetylene and ethylene as carbon feedstock and $\mathrm{Fe}, \mathrm{Ni}$ or $\mathrm{Co}$ as the catalyst, the temperature used for growing CNTs is typically in the range of $500-900^{\circ} \mathrm{C}$.

Fonseca et al. ${ }^{33}$ obtained huge amounts of MWNTs by deposition of $\mathrm{C}_{2} \mathrm{H}_{2}$ catalytically over $\mathrm{Co}$ and $\mathrm{Fe}$ catalysts supported on silica or zeolite. Combinations of metal catalysts, $\mathrm{Co} / \mathrm{Mo}, \mathrm{Co} / \mathrm{Fe}$ and $\mathrm{Co} / \mathrm{V}$ mixtures supported by either zeolite or alumina have also been used to decompose $\mathrm{C}_{2} \mathrm{H}_{2}$ to produce large amounts of MWNTs. ${ }^{34}$ Presence of Co ensures good quality MWNTs, whereas Fe is responsible for the thickness of the tubes.

Mixtures of $\mathrm{Co}$ and $\mathrm{V}$ in equal amounts produce the highest yields and thinnest tubes as compared to the other catalyst ratios. The choice of the carbon feedstock gas also affects the growth of CNTs. Baker et al. ${ }^{35}$ reported that unsaturated hydrocarbons such as $\mathrm{C}_{2} \mathrm{H}_{2}$ produce much higher yields and higher deposition rates than other saturated gases. Colomer et al..$^{36}$ by catalytic decomposition obtained SWNTs having high yields $(70-80 \%)$ utilizing $\mathrm{H}_{2} / \mathrm{CH}_{4}$ mixture over welldispersed metal particles $(\mathrm{Co}, \mathrm{Ni}, \mathrm{Fe})$ on $\mathrm{MgO}$ at $1000^{\circ} \mathrm{C}$. Maruyama et al. ${ }^{37}$ had developed high-quality SWNTs using alcohol as a carbon feedstock. This method not only finds application in mass production of SWNTs, but also for the direct production of SWNTs on nonmetallic substrates such as silicon and quartz.

\section{Other methods}

Catalytic pyrolysis of hydrocarbon: This method is commonly used for the mass production of CNTs. Using catalytic pyrolysis technique high purity CNTs are obtained so no need of purification to recover CNTs from the substrate. It involves the injection of catalyst as colloidal suspension with carbon feedstock right into the CVD chamber. Organometallic compounds that are used in the form of colloidal suspension include metallocenes, iron pentacarbonyl and iron (II phthalocyanine) ${ }^{38-44}$ These precursors on heating directly get converted to gaseous form, catalyst nanoparticles are formed when the compound is decomposed by heat. Different Organometallic compounds require different temperature conditions for sublimation and nanotube growth so a double stage furnace is needed. ${ }^{45,46} \mathrm{In}$ a short while ago, CNTs with tractable diameters from $\sim 1$ to $200 \mathrm{~nm}$ were produced by pyrolysis of iron phthalacyanine $(\mathrm{FePc})$ at $\sim 900^{\circ} \mathrm{C}$ under argon gas flow. ${ }^{47}$ The addition of small amount of thiophene $\left(\mathrm{C}_{4} \mathrm{H}_{4} \mathrm{~S}\right)$ to liquid hydrocarbons has also been proclaimed to promote the growth of SWNTs. ${ }^{48-50}$

Silane solution method: CNTs can also be produced using this method, in which a substrate such as stainless steel mesh or carbon paper was dipped in a silane solution of a metal catalyst like Co: $\mathrm{Ni}$ in the ratio 1:1; and a feedstock gas (ethylene) was fed through the substrate and the catalyst deposited thereon while the substrate was heated by the utilization of electrical current. Thus, a reaction takes place between the catalyst and the gas molecules to yield CNTs, supported on the conductive substrate. ${ }^{51}$

Purification of CNTs: CNT samples obtained from various methods discussed above are generally not pure, they consist of a mixture of various species of carbon such as amorphous carbon soot, carbon nanoparticles, a mixture of fullerenes and transition metals that were introduced as a catalyst during the synthesis. ${ }^{52-54}$ These impurities intervene with most of the aspired dominions of CNTs. For research purposes, it is of foremost importance that CNTs of high purity should be obtained and used. For example, when a particular type of CNT is required then it very crucial to purify the sample and determine that sample is pure as possible. Most commonly used industrial techniques include strong oxidation and acid refluxing techniques, but these techniques affect the structure of CNTs. Methods used for the purification of CNTs includes:

Oxidation: Oxidation of CNT sample is a good and one of the simplest ways to remove the carbonaceous impurities and to clear the metal surface. But this treatment has some flaws that by oxidation not only the impurities are getting oxidized but the CNT obtained are also getting oxidized. But it is also substantial to consider that the less proportion of CNT and more amounts of impurities are getting oxidized. One of the reasons for this selective oxidation can be that the impurities are having a more open structure as compared to CNTs; another reason for this can be that these impurities are more attached to the metal catalyst, which also acts as oxidizing agent. The efficiency of this method depends on lot of factors like:
i. Metal content
ii. Oxidation time
iii. Environment
iv. Oxidizing agent
v. Temperature..$^{53}$ 
Acid treatment: Acid treatment, in general, is utilized for removing of a metal catalyst. $\mathrm{HNO}_{3}$ is considered to be the best acid utilized for the treatment because it doesn't affect the SWNTs produced or in the solution it only affects the metal catalyst. ${ }^{54}$

Annealing: High-temperature conditions $\left(873-1873^{\circ} \mathrm{C}\right)$ are used in annealing method, at this high temperature the nanotubes are rearranged and the defects are consumed. The high temperature causes the impurities to pyrolyse. ${ }^{55}$

Ultrasonication: This method utilizes the employment of ultrasonic waves to separate the agglomerates of different nanoparticles by forced vibrations in order to become more dispersed. The separation of the particles is based on the nature of surfactant, solvent and reagent used..$^{55}$

Magnetic purification: In this technique inorganic nanoparticles like $\mathrm{ZrO}_{2}$ and $\mathrm{CaCO}_{3}$ are used to remove the ferromagnetic particles from their graphitic shells, this whole procedure is carried out in an ultrasonic bath. Ferromagnetic particles removed are then trapped with permanent magnetic poles. After subsequent chemical treatment high purity SWNTs are obtained. ${ }^{55}$

Micro Filtration: Microfiltration in simple terms means purification by filtration. In this technique micro filters of nominal pore size $0.20 \mu \mathrm{m}, 0.45 \mu \mathrm{m}$, and $0.80 \mu \mathrm{m}$ are used to trap SWNTs, MWNTs, and some nanoparticles but other impurities like nanoshells, metal catalysts, fullerenes and most of the nanoparticles which are present as impurities pass through the filter paper. Fernando et al. ${ }^{55}$ devised a way of setting apart fullerenes from nanoparticles, he found out that if the sample obtained was firstly soaked in $\mathrm{CS}_{2}$ solution then $\mathrm{CS}_{2}$ insoluble (CNTs) were trapped onto the paper and other impurities which are soluble in $\mathrm{CS}_{2}$ solution will pass away. ${ }^{55}$

Cutting: Cutting of CNTs can be induced by two ways either by chemical means or by mechanical means or by using a combination of these techniques. Chemical cutting of CNTs involves functionalization of CNTs first with fluorspar, then, the fluorated carbon will be driven off along the sidewall with pyrolisation in the form of $\mathrm{CF}_{4}$ or $\mathrm{COF}_{2}$. In this way chemically cut nanotubes will be obtained. Mechanical cutting of CNTs involve the utilization of ball mill, bonds are broken due to high friction between the nanotubes and nanoparticles which lead to the cutting of nanotubes in a very disordered way. A combination of these techniques can also be utilized to obtain better results, one such example is ultrasonically induces cutting in an acidic solution. Ultrasonic waves provide sufficient energy to the nanotubes to get separated from the catalyst surface and acid will rupture the defected sites..$^{55}$

Functionalization: As discussed earlier functionalization is a technique if making CNTs more soluble than the impurities by attachment of groups to the sidewalls of the tube so that they can be rapidly separated from the impurities like a metal catalyst, fullerenes, nanoshells etc by techniques such as filtration, annealing, chromatographic size separation. ${ }^{55}$

\section{Chromatography}

This method utilizes the application of two of the most popular chromatographic techniques known GCP (Gel Permeation Chromatography) and HPLC- SEC (High-performance liquid Chromatography - Size Exclusion Chromatography) to separate small quantities of SWNTs into fractions on the basis of length and diameter distribution. A solution containing SWNTs and other impurities are run through the above-mentioned columns; now according to the size of the SWNTs present in the solution, they will get separated. Smaller the molecule longer will be the pathway it will travel inside the column. So the SWNTs with the smallest size will be eluted first and then subsequently other SWNTs with larger sizes will be eluted. ${ }^{55}$

Pharmacology of CNTs: Pharmacokinetic and pharmacodynamic properties of CNTs depend to a large extent on their physicochemical properties such as:
i. Size
ii. Shape
iii. Aggregation
iv. Solubility
v. Dispersibility
vi. Chemical composition
vii. Surface functionalization ${ }^{56,57}$

CNT Toxic kinetics: Generally, the toxic harmful effects of CNT (Figure 5) arises from the combination of several factors, two of the utter most important factors include:

i. High surface area

ii. The intrinsic toxicity of the surface..$^{58}$

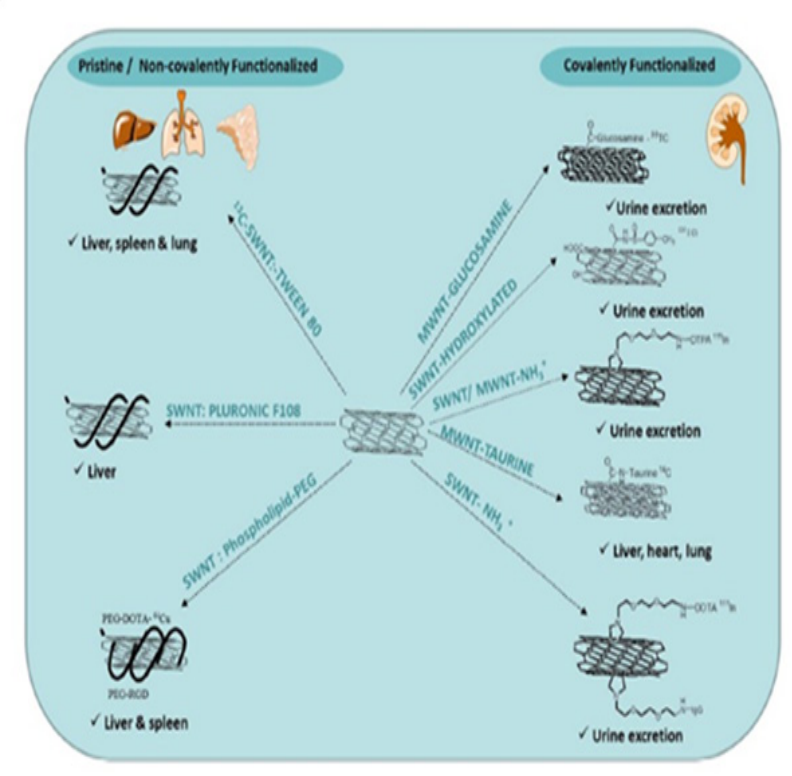

Figure 5 The current status of CNT bio distribution.

Conventional larger particles were discovered to be less toxic as compared with nanoparticles with the size range under $100 \mathrm{~nm}$, which were discovered to be more toxic to lungs, can redistribute from their site of deposition, can get away from the normal defense mechanism of the body and can alter the arrangement of normal human protein. Thus these particles can activate inflammatory and immunological responses and can also affect the usual operations of the tissues. ${ }^{59}$ Thus it can be inferred that nanotubes are toxic due to their nanosize range due to which there is a huge increase in total surface area which can elicit the unexpected toxicological effects on human body. ${ }^{60}$ 
It has been discovered that the contrasting functional groups have a different toxicological profile which adds on to the intrinsic toxicity of the CNT. Pristine batches of CNT just after synthesis contain several carbonaceous impurities and metallic nanoparticles which can severely add to the toxicokinetic profile of CNTs. ${ }^{60}$

Donaldson et al. ${ }^{61}$ have reported that the structural features of nanomaterials, like fiber shape, the length and the gathering status of the CNT, can also affect their local deposition in the lungs and can elicit immunological response following presentation to CNT.

Maynard et al. ${ }^{62}$ have investigated the release of toxic particles from unrefined SWNT material into the air and the potential routes of exposure of the workers in a small-scale production facility.

Huczko et al. ${ }^{63,64}$ examined the effects of CNT characteristics and the duration of exposure on the degree of respiratory distress observed together with any induced lung pathology.

Koyama et al. ${ }^{65}$ studied the effect of metal impurities on the toxicological profile and noticed the initiation of immunological toxicity and localized alopecia.

\section{Discussion}

\section{Applications of CNTs}

\section{Carrier for drug delivery:}

A. Many researchers have contributed in proving the effectiveness of CNTs as a possible carrier for drug delivery systems. ${ }^{66}$

B. Amphotericin B (an antifungal drug), when incorporated with carbon nanotubes, reported enhanced targeting. ${ }^{67}$

C. Cisplatin (anticancer drug), when incorporated with oxidized SWNHs, have reported to slow down the delivery of cisplatin in aqueous milieu, which increases the residence time of drug in the liver, which has been reported to be effective in terminating the growth of human lung cancer cell. ${ }^{68}$

D. Polyphosphazene platinum, an anticancer drug when given assimilated into nanotubes showed increased distribution, permeability and retention in the brain because of guarded lipophilicity of nanotubes. ${ }^{69}$

E. Doxorubicin, an antibiotic when given assimilated into nanotubes showed increased intracellular penetration. ${ }^{69}$

F. Oral Erythropoietin (EPO) administration has been made possible because of CNT- based carrier system, which was not possible earlier due to the instability of EPO in the gastric environment. ${ }^{69}$

G. The gelatin- CNT mixture (hydrogel) has been utilized as a potential carrier system for biomedical. ${ }^{69}$

H. CNTs can also be utilized as lubricant and glidant in pharmaceutical industries due to sliding nature of graphite layers bound with week Vander wall force. ${ }^{69}$

In genetic engineering: Nanotubes due to their specific structure and dominions are utilized as a carrier for gene therapy to treat cancer and genetic disorders. Their tubular nature has proved them as a vector in gene therapy. Nanotubes complexed with DNA were reported to deliver DNA before it was broken by cells defense system, boosting transfection significantly. In genetic engineering, CNTs and CNHs are used to manipulate genes and atoms in the development of bioimaging genomes, proteomics, and tissue engineering. The unwound DNA (single stranded) winds around SWNT by connecting its specific nucleotides and causes a change in its electrostatic property. This creates its potential application in diagnostics (polymerase chain reaction) and in therapeutics. Wrapping of carbon nanotubes by single-stranded DNA was discovered to be sequence-dependent, and hence can be used in DNA analysis. ${ }^{70}$

Biomedical applications: Bianco et al. $^{71}$ have prepared soluble CNTs and have covalently linked biologically active peptides with them. This was established for viral protein VP1 of FMDV exhibiting immunogenicity and eliciting an antibody response. In chemotherapy, drug entrapped nanotubes attack directly on viral ulcers and kill viruses. No antibodies were produced against the CNT backbone alone, suggesting that the nanotubes do not possess fundamental immunogenicity. The combination of all the described features of the vaccine system with the actuality that the capacities of the anti-peptide antibodies to neutralize FMDV have been enhanced has indicated that CNT can have a valuable part in the making of novel and effective vaccines.

In vitro studies by Kam et al. ${ }^{72}$ demonstrated selective cancer cell killing accomplished by hyperthermia due to the thermal conductivity of CNT into those cells.

Artificial implants: CNTs can be utilized as artificial implants without the problem of any host body rejection reaction. Normally host body shows rejection reaction for implants with post administration pain but when CNHs and CNTs have used incorporation with proteins and amino acids they successfully avoid all rejection reaction. This approach is being utilized with calcium filled CNTs, which can act as a bone substitute. ${ }^{73}$

Preservatives: $\mathrm{CNTs}$ and $\mathrm{CNHs}$ are having antioxidant properties. So they can be utilized for the preservation of drugs which are prone to oxidation. Their antioxidant properties are being employed in antiaging cosmetics with zinc oxide as sunscreen to prevent oxidation of important skin components. ${ }^{69}$

Diagnostic tool: Nanotubes have a specific property of showing fluorescence when incorporated with any biomolecule. So proteinencapsulated or protein/enzyme-filled nanotubes have fluorescent properties which can be utilized as implantable biosensors. For diagnostic purposes, CNTs can also be incorporated with magnetic materials, radioisotope enzymes which can be utilized as biosensors. ${ }^{74}$

CNTs role in cancer therapy: Many studies investigated that CNT was used for the cellular adsorption. ${ }^{75}$ Therefore, the diffusion of nanotubes interred and crossed cell membranes via an energyindependent non-endocytotic process. There are many fabricated neon drug target have been purposed for the folate receptors. ${ }^{76}$

Magnetic nanoparticles assembled CNTs: From the long time decades, nanoparticles have been used for the many targets. Magnetic CNTs have also showed encouraging outcomes as a MRI difference agent with elevated nuclear magnetic resonance relaxivities, catalysis and little cytotoxicity. CNTs engaged more professionally in bioimaging or biomedical applications. ${ }^{77}$

As biosensors: Biomedical industry CNT-integrated sensors are expected to bring about revolutionary alterations in many fields 
and exceptionally in the biomedical industry sector. One example is monitoring of the exposure to hazardous radiation like in nuclear plants/reactors or in chemical laboratories or industries. The main purpose in all these cases is to discover the exposure in different stages so that appropriate therapy may be given. CNT-based nanosensors are highly befitted as implantable sensors. Implanted sensors can be utilized for monitoring pulse, temperature, blood glucose, and also for diagnosing diseases. One such example is the utilization of nanotubes to track glucose levels in the blood, which would allow diabetics to examine their sugar levels without the need for taking samples by pricking their fingers. ${ }^{78}$

Till date various biosensor have been developed like as p-aminophenol-modified multi-walled carbon nanotubes used for detect vitamin C (ascorbic acid) through its electrochemical oxidation. ${ }^{79}$ Furthermore, electrochemical sensors for detecting chloramphenicol based on multi-walled tubes considered and successfully tested. ${ }^{80}$ Moreover, Sensors used for monitoring and controlling of human motions. ${ }^{81}$ These are now a few examples of how industry can obtain benefit of the vibrational, electrical, and mechanical properties of the multi-walled carbon nanotubes, which include DWNTs and TWNTs

\section{Limitations of CNTs}

Apart from having numerous applications CNTs also have certain limitations:

1. CNTs are not soluble in most of the solvents and their incompatibility in biological milieu restricts their use in medical science.

2. It is almost impossible to produce structurally and chemically reproducible batches of CNTs with almost identical characters, so batch to batch variation in properties may take place.

3. Difficulty in maintaining high quality and purity standards.

\section{Companies Selling and Developing CNT Products}

On the basis of the field of application various companies (Table 2) indulge themselves in the development of carbon nanotubes that comes in a variety of diameters, lengths, and functional group content. CNTs today are prepared for industrial applications in bulk quantities. Several CNT manufacturers have100 ton per year development capacity for MWNTs. ${ }^{82}$

Table 2 Companies Selling and Developing Cnt Products

\begin{tabular}{|c|c|c|c|}
\hline Company & URL & Field of application & Notes \\
\hline Adidas & www.adidas.com & Composites & Running shoe sole \\
\hline Amroy & http://www.amroy.fi/ & Composites & $\begin{array}{l}\text { Partnership with yachts, sports goods and wind turbine } \\
\text { blade manufactures }\end{array}$ \\
\hline \multirow[t]{2}{*}{ ANS } & $\begin{array}{l}\text { http://www. } \\
\text { appliednanostructuredsolutions.com }\end{array}$ & Composites & Synthetic fibers \\
\hline & & Energy & CNT based power for battery electrodes \\
\hline Baltic & http://www/balticyachts.com & Composites & Sailing yachts \\
\hline Canon & www.canon.com & Microelectronics & Field emission display; SED TV \\
\hline \multirow[t]{2}{*}{ Eikos } & www.eikos.com & Coating & Transparent conductors \\
\hline & & Energy & Photovoltaic cells \\
\hline Nanomix & www.nano.com & Biotechnology & Sensing and diagnostic \\
\hline Nokia & www.nokia.com & Coatings & Transparent conductors \\
\hline $\begin{array}{l}\text { Panasonic boston } \\
\text { Labs }\end{array}$ & www.panasonic.com & Coatings & Transparent conductors \\
\hline Porifera & http://poriferanano.com & Energy & Filtration membranes \\
\hline Samsung & www.samsung.com & Coatings & Transparent conductors \\
\hline Yonex & www.younex.com & Composites & Badminton rackets, tennis rackets \\
\hline
\end{tabular}

\section{Conclusion}

This review presents an overview of carbon nanotubes their structure, morphology, synthesis and purification methods along with their properties, applications, limitation and market. The distinct structural properties apart from their limitations carbon nanotubes prove that they have great potential for being a useful carrier in pharmaceutical nano delivery. Scientists are trying to research the dominions of CNTs heavily and deeply with many of the known properties. SWNTs and MWNTs have already proven their potential as being a better alternative to the existing drug delivery systems. Among the various techniques shown for synthesis in the review, CVD 
originated to be the best method for large-scale synthesis of MWNTs and small scale synthesis of SWNTs. But the large scale synthesis of SWNTs is still a challenge for scientists. Nanotubes truly shorten the gap between the micro realm and the macro world and are destined to be the emerging star of future technology. With the prospect of nanotechnology, cancer treatment and innovative new answers to lifethreatening diseases the importance of nanotubes in medical science has increased in last few decades. They can pass through membranes; carry therapeutic drugs, vaccines, nucleic acid deep into targets which were previously unreachable. Overall recent studies have shown that carbon nanotubes have a very bright future in all fields of science.

\section{Acknowledgements}

The authors would like to express their gratitude to Babasaheb Bhimrao Ambedkar University (a Central University) Lucknow and Kumaun University, Bhimtal campus, Bhimtal, Uttarakhand for providing the research data facilities.

\section{Conflict of interest}

The author declares no conflict of interest.

\section{References}

1. http://en.wikipedia.org/wiki/carbon_nanotube.

2. Foldvari M, Bagonluri M. Carbon nanotubes as functional excipients for nanomedicines: I. pharmaceutical properties. Nanomedicine. 2008;4(3):173-182.

3. Iijima S, Yudasaka M, Yamada R, et al. Nano-aggregates of single walled graphitic carbon nano-horns. Chem Phys Lett. 1999;309:163-170

4. Dresselhaus MS, Dresselhaus G, Charlier JC, et al. Electronic. Thermal and mechanical properties of carbon nanotubes. Philos Transact A Math Phys Eng Sci. 2004;362:2065-2098.

5. Cientifica. Wearables, Smart Textiles and Nanotechnology: Applications. Technologies and markets; 2016

6. Anazawa K, Shimotani K, Manabe C, et al. High purity carbon nano tube synthesis method. Applied Physics Letters. 2002;81:739-741.

7. Bianco A, Kosteralos K, Partidos CD, et al. Biomedical applications of functionalized carbon nanotubes. Chem Commun (camb). 2005; 5:571577

8. Bianco A, Hoebeke J, Kostarelos K, et al. Carbon nanotubes: on road to deliver. Current Drug Deliv. 2005;2(3):253-259.

9. Sinnott SB, Andrews R. Carbon nanotubes: synthesis, properties and applications. Critical Reviews in Solid State Mat Sci. 2001;26(3):145249.

10. Karthikeyan S, Mahalingam P, Karthik M. Large scale synthesis of carbon nanotubes. E-J of Chem. 2009;6(1):1-12.

11. Journet C, Maser WK, Bernier P, et al. Large-scale production of single-walled carbon nanotubes by the electric-arc technique. Nature. 1997;388:756-758.

12. Shi Z, Lian Y, Liao FH, et al. Large scale synthesis of single-wal carbon nanotubes by arc-discharge method. J Phys Chem Solids. 2000;61(7):1031-1036.

13. Teo KBK, Singh C, Chhowalla M, et al. Catalytic synthesis of carbon nanotubes and nanofibers. Am Sci Pub. 2003;1:665-668

14. Paradise M, Goswami T. Carbon nanotubes-production and industrial application. Mat Design. 2007;28(5):1477-1489.

15. Pharmainfo.net carbon nanotubes; 2016.
16. Ren ZF, Huang ZP, Xu JW, et al. Synthesis of large arrays of well-aligned carbon nanotubes on glass. Science. 1998;282(5391):1105-1107

17. Chen Y, Wang ZL, Yin JS, et al. Well - aligned graphitic nanofibers synthesized by plasma assisted chemical vapor deposition. Chem Phys Lett. 1997;272(3-4):178-182.

18. Chen Y, Patel S, Ye YG, et al. Field emission from aligned high density graphitic nanofibers. Appl Phys Lett. 1998;73(15):2119-2121.

19. Huang ZP, Wu JW, Ren ZE, et al. Growth of highly oriented carbon nanotubes by plasma-enhanced hot filament chemical vapor deposition. Appl Phys Lett. 1998;73(26):3845-3847.

20. Bower C, Zhu W, Jin SH, et al. Plasma-induced alignment of carbon nanotubes. Appl Phys Lett. 2000;77(6):830-832.

21. Qin LC, Zhou D, Krauss AR, et al. Growing carbon nanotubes by microwave plasma-enhanced chemical vapor deposition. Appl Phys Lett. 1998;72(26):3437.

22. Wang N, Yao BD. Nucleation and growth of well-aligned, uniform-sized carbon nanotubes by microwave plasma chemical vapor deposition. Appl Phys Lett. 2001;78(25):4028-4030.

23. Okai M, Muncyoshi T, Yaguchi T, et al. Structure of carbon nanotubes grown by microwave-plasma-enhanced chemical vapor deposition. Appl Phys Lett. 2000;77(21):3468

24. Choi YC, Shin YM, Lim SC, et al. Effect of surface morphology of Ni thin film on the growth of aligned carbon nanotubes by microwave plasmaenhanced chemical vapor deposition. J Appl Phys. 2000;88(8):48984903 .

25. Merkulov VI, Lowndes DH, Wei YY, et al. Patterned growth of individual and multiple vertically aligned carbon nanofibers. Appl Phys Lett. 2000;76(24):3555.

26. Chhowalla M, Teo KBK, Ducati C, et al. Growth process conditions of vertically aligned carbon nanotubes using plasma enhanced chemical vapor deposition. J Appl Phys. 2001;90(10):5308-5317.

27. Teo KBK, Lee SB, Chhowalla M, et al. Plasma enhanced chemical vapour deposition carbon nanotubes/nanofibers how uniform do they grow. Nanotechnology. 2003;14(2):204

28. Li J, Stevens R, Delzeit L, et al. Electronic properties of multiwalled carbon nanotubes in an embedded vertical array. Appl Phys Lett. 2002;81(5):910-912.

29. Delzeit L, Aninch IM, Cruden BA, et al. Growth of multiwall carbon nanotubes in an inductively coupled plasma reactor. J Appl Phys. 2002;91(9):6027-6033

30. Boskovic BO, Stolojan V, Khan RUA, et al. Large-area synthesis of carbon nanofibers at room temperature. Nature Mater. 2002;1(3):165168 .

31. Lee KY, Fujimoto K, Ohkura S, et al. Synthesis of vertically aligned carbon nanofiber films by RF magnetron sputtering. Mater Res Soc Symp Proc. 2001;675:W3.1.1-W3.1.4.

32. Park D, Kim YH, Lee JK. Synthesis of carbon nanotubes on metallic substrates by a sequential combination of PECVD and thermal CVD Carbon. 2003;41(5):1025-1029.

33. Fonseca A, Hernadi K, Nagy JB, et al. Optimization of catalytic production and purification of buckytubes. J Mol Catal A. 1996;107(13):159-168.

34. Williems I, Konya Z, Colomer JF, et al. Control of the outer diameter of thin carbon nanotubes synthesized by catalytic decomposition of hydrocarbons. Chem Phys Lett. 2000;317:71-76.

35. Walker JPL, Thrower PA. Chemistry and Physics of Carbon. 4th ed. New York, USA: Marcel Dekker; 1978. p. 83. 
36. Colomer JF, Stephan C, Lefrant S, et al. Large-scale synthesis of singlewall carbon nanotubes by chemical vapor deposition (CCVD) method Chem Phys Lett. 2000;317:83-89.

37. Maruyama S, Murakami Y, Shibuta Y, et al. Generation of single-walled carbon nanotubes from alcohol and generation mechanism by molecular dynamics simulations. J Nanosci Nanotechnol. 2004;4(4):360-367.

38. Endo M, Takeuchi K, Kobori K, et al. Prolytic carbon nanotube from vapour grown carbon fibers. Carbon. 1995;33(7):873-881.

39. Sen R, Govindaraj A, Rao CNR. Carbon nanotubes by the metallocene route. Chem Phys Lett. 1997;267(3-4):276-280.

40. Satishkumar BC, Govindaraj A, Sen R, et al. Single-walled nanotubes by the pyrolysis of acetylene-Organometallic mixtures. Chem Phys Lett. 1998;293(1-2):47-52.

41. Huang SM, Dai LM, Mau AWH. Patterned growth and contact transfer of well aligned carbon nanotube film. J Phys Chem B. 1999;103(21):42234227.

42. Yang YY, Huang SM, He HZ, et al. Patterned growth of well aligned carbon nanotubes: A photolithographic approach. $J$ Am Chem Soc. 1999;121(46):10832-10833.

43. Li DC, Wang ZL, Huang SM, et al. Structure and growth of aligned carbon nanotube films by pyrolysis. Chem Phys Lett. 2000;316(5-6):349-355.

44. Singh C, Shaffer MSP, Windle AH. Production of controlled architectures of aligned carbon nanotubes by an injection chemical vapour deposition method. Carbon. 2003;41(2):363-368.

45. Singh C, Shaffer MSP, Koziol KKK, et al. Towards the production of large-scale aligned carbon nanotubes. Chem Phys Lett. 2003;372(56):860-865

46. Sen R, Govindaraj A, Rao CNR. Metal-filled and hollow carbon nanotubes obtained by the decomposition of metal containing free precursor molecules. Chem Mater. 1997;9(10):2078-2081.

47. Harutyunyan AR, Chen G, Eklund PC. Self assembled growth of singlewalled carbon nanotubes by pyrolysis of metalorganic precursor. Appl Phys Lett. 2003;82:4794-4796.

48. Zhu HW, Xu CL, Wu DH, et al. Direct synthesis of long single-walled carbon nanotube strands. Science. 2002;296(5569):884-886.

49. Ago H, Ohshima S, Uchida K, et al. Gas-phase synthesis of single wall carbon nanotubes from colloidal solution of metal nanoparticles. $J$ Phys Chem B. 2001;105(43):10453-10456.

50. Cheng HM, Li F, Su G, et al. Large-scale and low-cost synthesis of singlewalled carbon nanotubes by the catalytic pyrolysis of hydrocarbons. Appl Phys Lett. 1998;72:3282-3284.

51. Process for preparing carbon nanotubes. United States Patent; 6:887

52. Ebbesen TW, Ajayan PM. Large scale synthesis of carbon nanotubes. Nature. 1992;358:220-222.

53. Saito Y, Kawabata K, Okuda M. Single-layered carbon nanotubes synthesized by catalytic assistance of rare-earths in a carbon arc. J Phys Chem. 1995;99(43):16076-16079.

54. Thess A, Lee R, Nikolaev P, et al. Crystalline ropes of metallic carbon nanotubes. Science. 1996;273(5274):483-487.

55. Fernando Ka, Lin Y, Sun YP. High aqueous solubility of functionalized single-walled carbon nanotubes. Langmuir. 2004;20(11):4777-4778.

56. Kostarelos K. Rational design and engineering of delivery systems for therapeutics: biomedical exercises in colloid and surface science. $A d v$ Colloid Interface Sci. 2003;106:147-168.

57. Nel A, Xia T, Maedler L, et al. Toxic potential of materials at the nano level. Science. 2006;311(5761):622-627.
58. Ali Boucetta H, Kostarelos K. Pharmacology of carbon nanotubes: Toxicokinetics, excretion and tissue accumulation. Elsevier. 2013;65(15):2111-2119.

59. Donaldson K, Stone V, Tran CL, et al. Nanotoxicology Occup Environ M. 2004;61(9):727-728.

60. Lacerda L, Bianco A, Prato M, et al. Carbon nanotubes as nanomedicines: From toxicology to pharmacology. Adv Drug Deli. 2006;58(14):1460 1470

61. Donaldson K, Aitken R, Tran L, et al. Carbon nanotubes: a review of their properties in relation to their pulmonary toxicology and workplace safety. Toxicol Sci. 2006;92(1):5-22.

62. Maynard A, Baron P, Foley M, et al. Exposure of carbon nanotube material: aerosol release during the handling of unrefined single-walled carbon nanotube material. J Toxicol Environ Health. 2004;67(1):87-107.

63. Huczko A, Lange H, Calko E, et al. Physiological testing of carbon nanotubes: are they asbestos-like? Fuller Sci Technol. 2001;9:251-254.

64. Huczko A, Lange H, Bystrzejewski M, et al. Pulmonary toxicity of 1-D nanocarbon materials, Fuller. Nanotubes Carbon Nanostruct. 2005; $13: 141-145$.

65. Koyama S, Kim YA, Hayashi T, et al. In vivo immunological toxicity in mice of carbon nanotubes with impurities. Carbon. 2009;47(5):13651372

66. Sebastien W, Giorgia W, Monica P, et al. Targeted delivery of amphotericin $\mathrm{b}$ to cells by using functionalized carbon nanotubes. Angewandte Chemie. $2005 ; 117: 6516-6520$

67. Barroug A, Glimcher M. Hydroxyapatite crystals as a local delivery system for cisplatin: adsorption and release of cisplatin in vitro. J Orthop Res. 2002;20(2):274-280.

68. Ajima K, Yudasaka M, Murakami T, et al. Carbon nanohorns as anticancer drug carriers. Mol Pharm. 2005;2(6):475-480.

69. Pai P, Nair K, Jamade S, et al. Pharmaceutical applications of carbon tubes and nanohorns. Current Pharma research Journal. 2006;1:11-15.

70. Pantarotto D, Partidos C, Hoebeke J, et al. Immunization with peptidefunctionalized carbon Nanotubes enhances virus-specific neutralizing antibody responses. Chem Biol. 2003;10(10):961-966.

71. Nanotsunami c2003-2009.

72. Kam NWS, O’Connell M, Wisdom JA, et al. Carbon nanotubes as multifunctional biological transporters and near infrared agents for selective cancer cell destruction. Proc Natl Acad Sci USA. 2005;102(33):11600-11605.

73. Deng P, Xu Z, Li J. Simultaneous determination of ascorbic acid and rutin in pharmaceutical preparations with electrochemical method based on multi-walled carbon nanotubes-chitosan composite film modified electrode. J Pharm Biomed Anal. 2013;76:234-242.

74. Kuznetsova A, Mawhinney D. Enhancement of adsorption inside of single-walled nanotubes: opening the entry ports. Chem Phys Lett. 2000;321:292-296.

75. Ghasemvand F, Biazar E, Tavakolifard S. Synthesis and valuation of multi-wall carbon nanotubepaclitaxel complexas an anti-cancer agent. International journal of polymeric materials. 2014;63:898-908.

76. Baradaran Rafii A, Biazar E, Heidari keshel S. Cellular response of limbal stem cells on polycaprolactone nanofibrous scaffolds for ocular epithelial regeneration. Curr Eye Res. 2014;41(3):326-333.

77. Biazar E, Tavakolifard S. Modification of carbon nanotubes as an effective solution for cancer therapy. Nano Biomed Eng. 2016;8(3):144-160.

78. Prabhakar R Bandaru. Electrical Properties and Applications of Carbon Nanotube Structures. J Nanosci Nanotechnol. 2007;7(4-5):1-29. 
79. Yang G, Zhao F. Electrochemical sensor for chloramphenicol based on novel multiwalled carbon nanotubes@molecularly imprinted polymer Biosens Bioelectron. 2015;64(190):416-422.

80. Ryu S, Lee P, Chou JB, et al. Extremely elastic wearable carbon nanotube fiber strain sensor for monitoring of human motion. ACS Nano. 2015;9(6):5929-5936

81. Ansari R, Ajori S, Ameri A. Stability characteristics and structural properties of single and double-walled boron-nitride nanotubes under physical adsorption of Flavin mononucleotide (FMN) in aqueous environment using molecular dynamics simulations. Applied Surface Science. 2016;366:233-244.
82. Volder MFLD, Tawfick SH, Baughman RH, et al. Carbon nanotubes: Present and future commercial applications. Science. 2013;339(6119):535-539. 